\title{
Management of Open Globe Injuries and Concern About Sympathetic Ophthalmia: A Case Report
}

\author{
Can Ozturker,, ${ }^{1}$ Pelin Kaynak, ${ }^{2}$ Gamze Ozturk Karabulut, ${ }^{3}$ Korhan Fazil, ${ }^{3}$ Yusuf Yildirim, ${ }^{3}$ Osman Bulut Ocak ${ }^{3}$ \\ ${ }^{1}$ Department of Ophthalmology, Istanbul University, Istanbul Faculty of Medicine, Istanbul, Turkey \\ ${ }^{2}$ Rufus Laser \& Ophthalmic Surgery Center, Istanbul, Turkey \\ ${ }^{3}$ University of Health Sciences Beyoglu Eye Training and Research Hospital, Istanbul, Turkey
}

\begin{abstract}
An I8-year-old male with an open globe injury, eyelid lacerations, and orbital wall fractures related to severe blunt trauma was referred to the clinic for primary evisceration and eyelid repair. As the patient refused the removal of the eye, the globe, eyelids, and canaliculi were sutured primarily. A month later, the patient accepted the removal of the eye due to progressive phthisis bulbi and underwent evisceration 5 weeks after the injury. He was followed up for 2 years after the second surgery and had an acceptable cosmetic result without any complication. Although very rare, it is very important to remember that there is a risk of sympathetic ophthalmia in severe eye injuries, though prophylaxis by removing the eye remains controversial.
\end{abstract}

Keywords: Canalicular laceration, enucleation, evisceration, sympathetic ophthalmia, trauma.

\section{Introduction}

Open globe injuries are one of the main reasons for the removal of an eye in order to avoid sympathetic ophthalmia (SO), which is a devastating, though uncommon, bilateral granulomatous panuveitis following uveal trauma to one eye. The injured eye is referred to as the inciting eye, while the fellow eye is called the sympathizing eye (I). The prevalence of SO after eye injury is estimated to be between $0.1 \%$ and $0.3 \%(2-4)$.

Due to its very low incidence, it is controversial whether or not $\mathrm{SO}$ can be prevented by removing the eye after trauma (5-7). Even if it occurs, there may be a good prognosis with early diagnosis and the use of modern immunotherapies (8). There is no scientific consensus on the technique and timing of prophylactic surgery (9-12).

The purpose of this case report was to discuss the need for the removal of an injured blind eye after severe trauma and the choice of surgical procedure, considering the risk of SO.

\section{Case Report}

An 18-year-old male with a recent history of a thrown cylindrical metal object having caused trauma to his left eye was referred to the clinic for primary evisceration and eyelid repair. The patient was suffering from open globe injury and multiple upper and lower eyelid lacerations involving both canaliculi (Fig. I).

The injured eye had no light perception and had a large corneal-scleral rupture, extending vertically from the upper to the lower quadrant on slit-lamp examination. An orbital computed tomography scan revealed multiple fractures of the upper, medial, and lower orbital walls, as well as the maxillary bone (Fig. 2).

Despite being informed about the risk of $\mathrm{SO}$ and the unlikelihood of visual recovery, the patient did not give consent for the removal of the eye. Accordingly, the globe and the eyelids were sutured primarily and the canaliculi were repaired using a self-retaining bicanalicular silicone stent on 

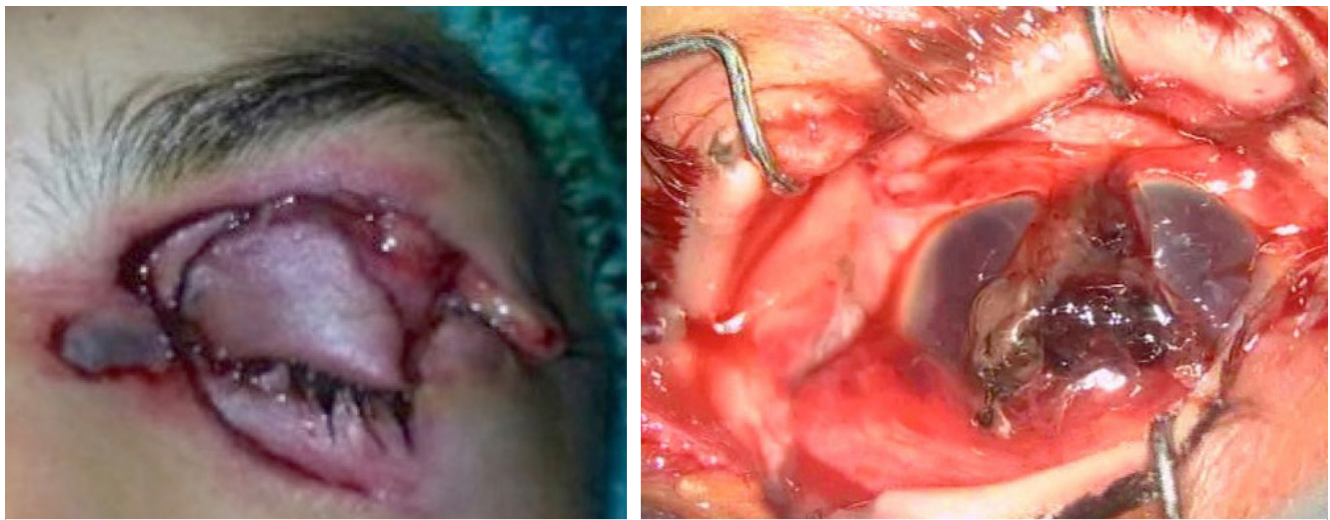

Figure I. The extent of the injury.

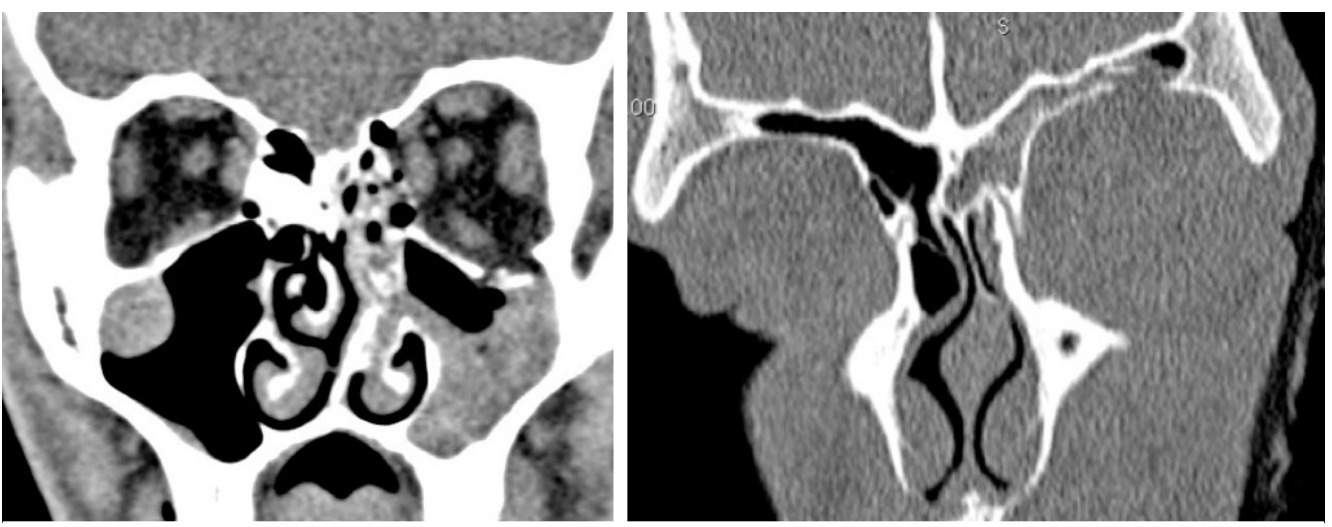

Figure 2. Orbital wall fractures seen on a computed tomography scan.
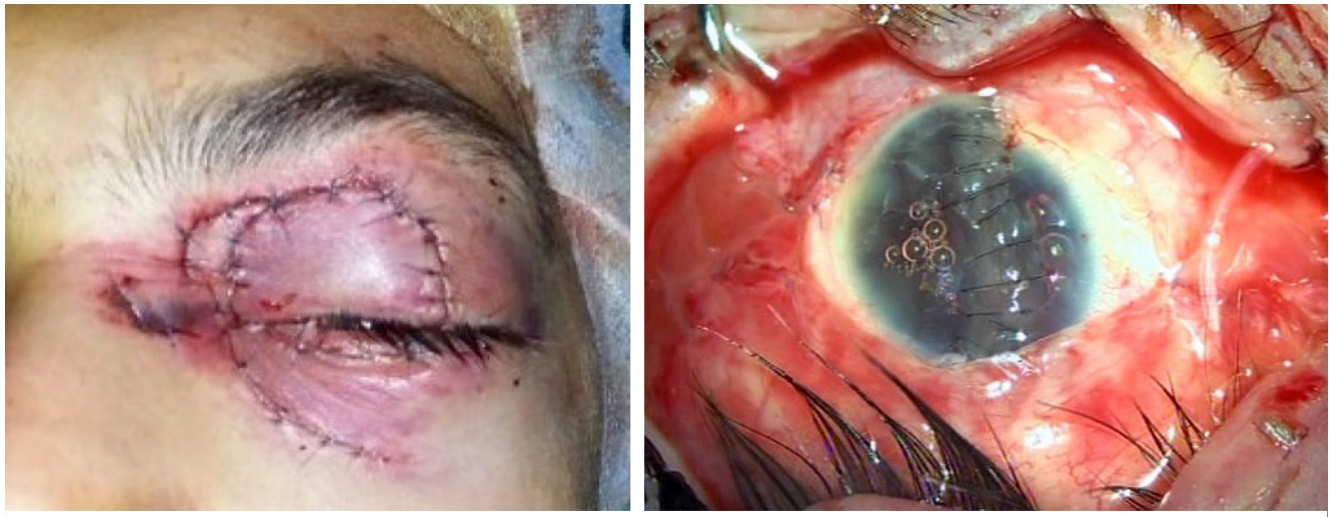

Figure 3. The conclusion of surgery.

the same day of the injury (Fig. 3). Due to a small quantity of prolapsing orbital content, reconstruction of the orbital walls was not planned for the surgery.

One month later, the eye started to develop phthisis and was without any visual recovery (Fig. 4). Concerned about cosmesis, the patient agreed to have the eye removed, and evisceration with a 22-mm acrylic implant was performed 5 weeks after the initial injury.

A silicone stent was removed 3 months after the primary repair and a custom-made prosthetic eye was fitted 3 months after the evisceration. The patient was satisfied with the cosmetic result and had neither epiphora nor SO during 2 years of follow-up. Thereafter, he was discharged from follow-up and recommended to see his ocularist on a yearly basis (Figs. 5, 6).

\section{Discussion}

There is no clear information about the true prevalence of SO after ocular injury, but it is estimated to be between $0.1 \%$ and $0.3 \%$, according to the current literature (2-4). There are 


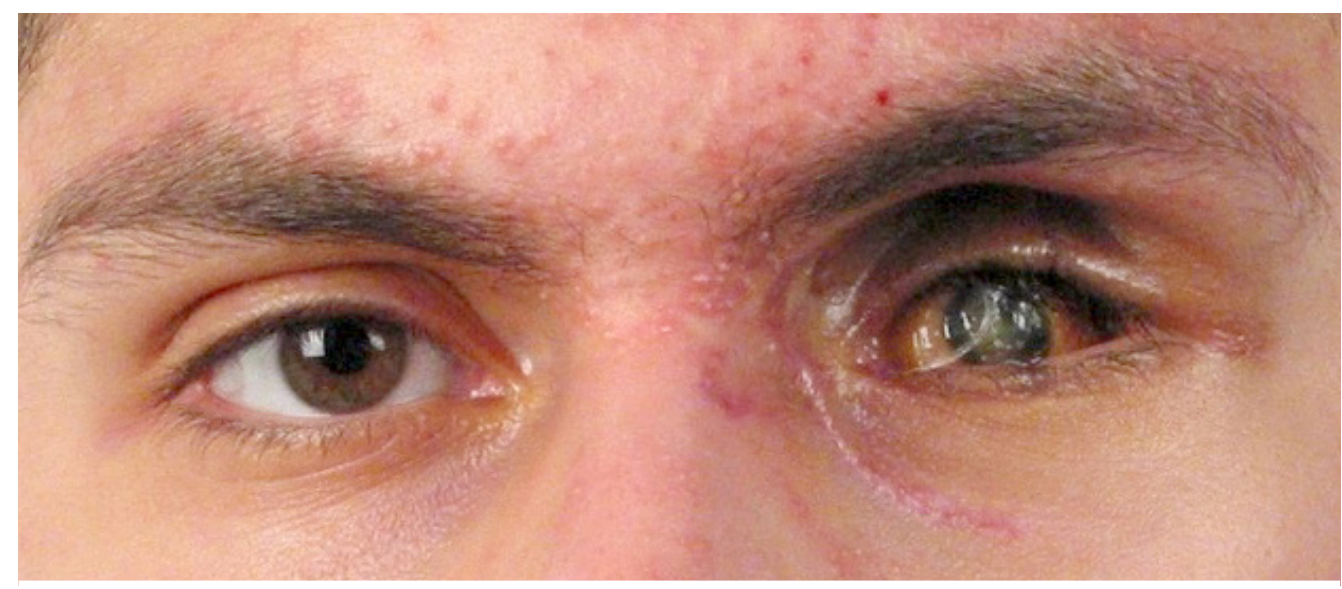

Figure 4. One month after the primary repair, with visible phythisis bulbi.
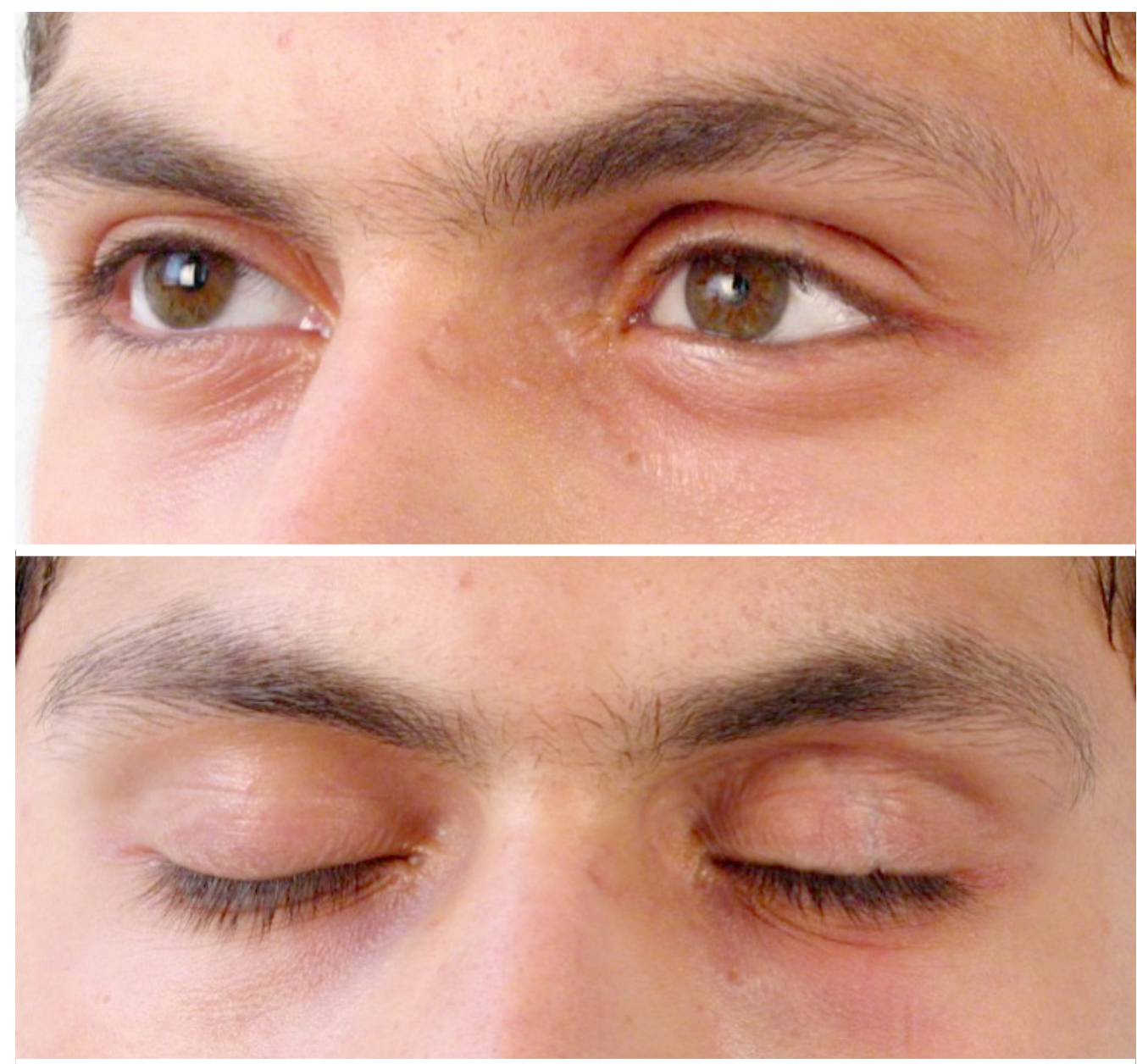

Figure 5. One year after the primary repair.

2 main questions in the management of severe eye trauma: Should the injured eye be removed as a prophylaxis for SO and what is the ideal surgical technique for this?

In general, it is recommended that a traumatized eye be removed within a time frame of 10 days to 2 weeks following a penetrating injury. Despite that, Savar et al. (10) reported in 2009 that among 660 open globe injuries, only 55 eyes had undergone enucleation. This review of cases revealed that only 2 patients $(0.3 \%)$ developed SO. These patients had not undergone enucleation and maintained good vision in the fellow eye after medical treatment. In prospective surveillance for SO in UK and Ireland, Kilmartin et al. (8) found that $75 \%$ of cases had a visual acuity of 6/I2 or better at I year, which was attributed to early diagnosis and modern immunothera- 

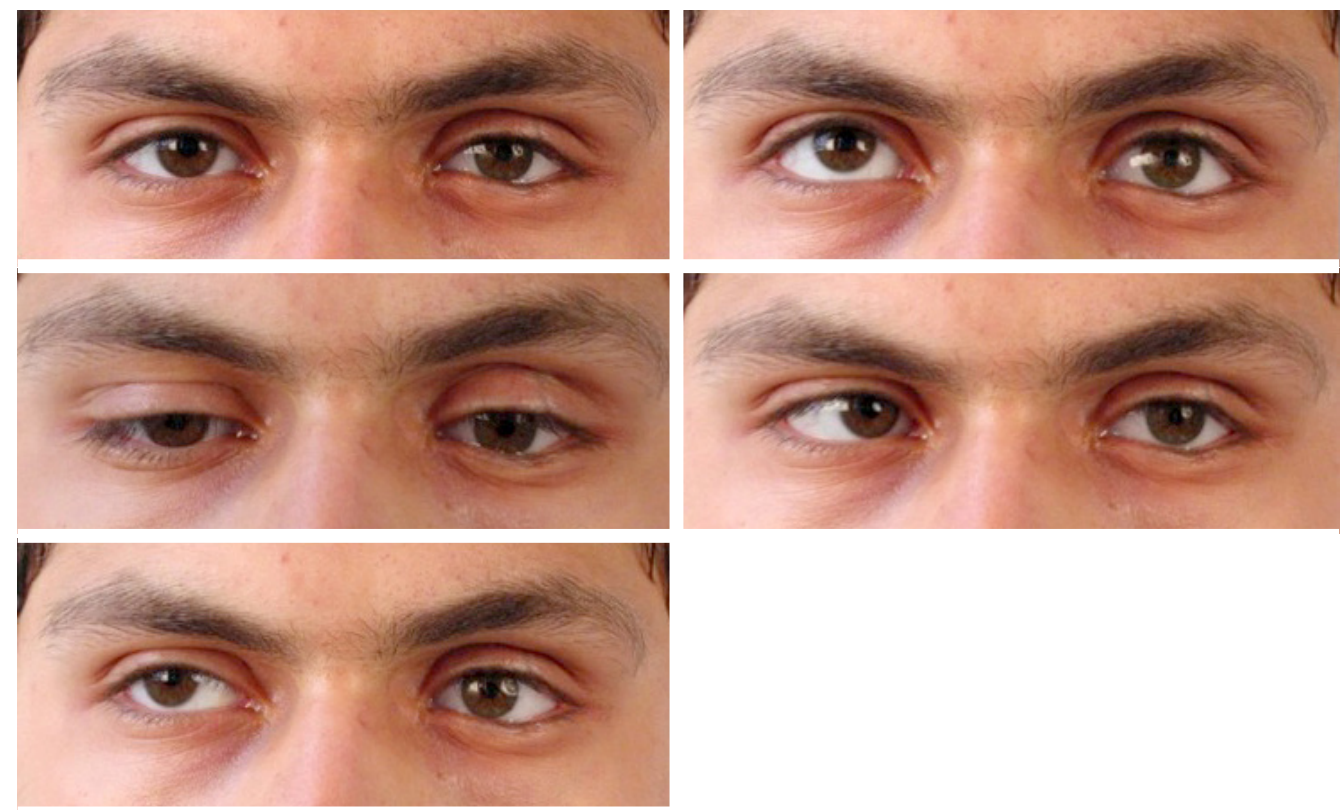

Figure 6. Movement of the prosthetic eye.

pies by the authors.

This published information brings up the question of how necessary it is to remove an injured eye to prevent SO. Using hypothetical calculations, Bellan (13) proposed that between 908 (assumed SO rate of $3.1 \%$ ) to 9999 (assumed SO rate of $0.28 \%$ ) eyes would be enucleated prophylactically to prevent just I case of legal blindness.

Although enucleation may be the oldest operation in the history of ophthalmology, going back to $2600 \mathrm{BC}$, evisceration gained popularity over enucleation among ophthalmologists in the last century due to its cosmetic and functional advantages and its simplicity (12). First described by Bear in 1817 , evisceration causes less disturbance to the delicate orbital septal anatomy, preserves the physiological function of the eye muscles, and maintains the sclera as a barrier holding the orbital implant. These features are the keys to a healthy anophthalmic socket, providing good motility for the eye prosthesis and preventing implant exposure (9).

However, reports of SO cases following evisceration, first by Green at al. (6) in 1972 and then by others (7) led to a distrust in this technique in terms of preventing SO. A survey conducted by Levine et al. (9) among the members of the American Society of Ophthalmic Plastic and Reconstructive Surgery in 1996 revealed that enucleation was the procedure of choice in $72.3 \%$ of cases. In the same survey, members of the Uveitis Society and the Eastern Ophthalmic Pathology Society preferred enucleation in more than $90 \%$ of cases.

Nevertheless, there are many large published series of evisceration without any postoperative SO during follow-up (9). In their article comparing evisceration and enucleation from the ocularist's perspective, Timothy et al. (II) men- tioned that their review of the literature did not reveal any published cases of SO following evisceration in the last 25 years.

Unfortunately, in trauma cases it is difficult to know whether SO is a result of the original trauma or the evisceration itself. In 2013, Tseng et al. (5) presented an interesting case of pathologically proven SO following enucleation of a painful phthisical eye with a history of multiple intraocular surgeries. Six weeks after the surgery, a histopathological examination of the enucleated eye revealed findings consistent with SO and the fellow eye was also clinically affected. The authors concluded that SO was related to previous intraocular surgeries rather than the enucleation, but had the eye have been eviscerated in his case, the SO could have been attributed to evisceration itself, due to a lack of pathological evidence.

On the other hand, in a large series of 85 SO cases reported by Galor et al. (14), 19 patients $(22 \%)$ had a history of enucleation in the inciting eye, suggesting that even enucleation may not be as reliable as it is assumed to be as prophylaxis against SO.

\section{Conclusion}

The incidence of SO after open globe injury is very low, and the prevention of SO by evisceration or enucleation is controversial. Patients with this condition may need time to accept the loss of their eye. During this period, the risk of SO, surgical and medical treatment options, and possible complications for each scenario must be discussed with the patient in detail, so that they can make the relevant decisions, which will affect them for the rest of their life. 


\section{Disclosures}

Informed consent: Written informed consent was obtained from the patient for the publication of the case report and the accompanying images.

Peer-review: Externally peer-reviewed.

Conflict of Interest: None declared.

Authorship Contributions: Involved in design and conduct of the study (CO, PK, YY); preparation and review of the study (PK, $\mathrm{CO})$; data collection (GOK, KF, BO).

\section{References}

I. Castiblanco CP, Adelman RA. Sympathetic ophthalmia. Graefes Arch Clin Exp Ophthalmol 2009;247:289-302. [CrossRef]

2. Allen JC. Sympathetic ophthalmia, a disappearing disease. JAMA 1969;209:1090. [CrossRef]

3. Liddy L, Stuart J. Sympathetic ophthalmia in Canada. Can J Ophthalmol 1972;7:157-9.

4. Kraus-Mackiw E, Müller-Ruchholtz W. Sympathetic eye diseases: diagnosis and therapy. Klin Monbl Augenheilkd 1980; I76:I31-9.

5. Tseng VL, Matoso A, Hofmann RJ. Sympathetic ophthalmia following enucleation. Graefes Arch Clin Exp Ophthalmol 2013;25I:393-4. [CrossRef]

6. Green WR, Maumenee AE, Sanders TE, Smith ME. Sympathetic uveitis following evisceration. Trans Am Acad Ophthalmol
Otolaryngol 1972;76:625-44.

7. Griepentrog GJ, Lucarelli MJ, Albert DM, Nork TM. Sympathetic ophthalmia following evisceration: a rare case. Ophthal Plast Reconstr Surg 2005;21:316-8. [CrossRef]

8. Kilmartin DJ, Forrester JV, Dick AD. Tacrolimus (FK506) in failed cyclosporin A therapy in endogenous posterior uveitis. Ocul Immunol Inflamm 1998;6: I0I-9. [CrossRef]

9. Levine MR, Pou CR, Lash RH. The 1998 Wendell Hughes Lecture. Evisceration: is sympathetic ophthalmia a concern in the new millennium? Ophthal Plast Reconstr Surg 1999;15:4-8.

10. Savar A, Andreoli MT, Kloek CE, Andreoli CM. Enucleation for open globe injury. Am J Ophthalmol 2009; |47:595-600.el.

I I. Timothy NH, Freilich DE, Linberg JV. Evisceration versus enucleation from the ocularist's perspective. Ophthal Plast Reconstr Surg 2003;19:417-20. [CrossRef]

I2. Bilyk JR. Enucleation, evisceration, and sympathetic ophthalmia. Curr Opin Ophthalmol 2000; I 1:372-86. [CrossRef]

13. Bellan L. Sympathetic ophthalmia: a case report and review of the need for prophylacticenucleation. Can J Ophthalmol 1999;34:95-8.

14. Galor A, Davis JL, Flynn HW Jr, Feuer WJ, Dubovy SR, Setlur $\mathrm{V}$, et al. Sympathetic ophthalmia: incidence of ocular complications and vision loss in the sympathizing eye. Am J Ophthalmol 2009; |48:704-10.e2. [CrossRef] 